\title{
Integralidade da Atuação do PSF nos Diferentes Níveis de Atenção à Saúde
}

Isabela Corrêa Vogel Koury - Professora de Saúde da Família da FMP

Maria Cristina Ezequiel - Diretora e Supervisora de Clínica Médica da FMP

Carlos Gazanego - Médico de Família da FMP

Palavras-Chave: Atenção Primária à Saúde, sistema de referência e contra-referência, integralidade.

Este relato de caso tem como objetivo relatar o resumo do atendimento de um paciente com história de “dor em membros inferiores” que teve inicialmente o diagnóstico de artrose feito em um serviço de Pronto Atendimento. A posteriori foi avaliado na Unidade de Saúde da Família, e em conjunto com a Secretaria de Saúde local e Centro de Referência em outro Município, tendo sido estabelecido o diagnóstico conclusivo de insuficiência arterial aguda e aneurisma de aorta abdominal. A trajetória do paciente até o estabelecimento do diagnóstico e do encaminhamento para as intervenções apropriadas e oportunas demonstra a importância do atendimento com base nos princípios do vínculo, da continuidade, da integralidade, com a retaguarda de um sistema de referência e contrareferência estruturado.

Os serviços de saúde precisam estar organizados em níveis de complexidade crescente, com tecnologia adequada para cada nível, potencializando a resolutividade. A Saúde da Família, como atenção primária, guarda relação de intercomplementaridade com outros níveis de atenção em saúde, não sendo, portanto, independente.

Quando se busca orientar a organização dos serviços de saúde pelos princípios da integralidade, o que se procura é ampliar as percepções das necessidades dos grupos e questionar-se sobre as melhores formas de dar respostas a tais necessidades. Assim, a Saúde da Família deve trabalhar em estreita relação com outros níveis de atenção à saúde para que possa enfrentar os problemas adequadamente. 


\section{RELATO DO CASO}

Paciente do sexo masculino, setenta anos, branco, casado, pintor, natural de Petrópolis, residente em uma das escadarias da Comunidade Estrada da Saudade do Município de Petrópolis-RJ. Procurou, sob livre demanda, a Unidade de Saúde da Família desta comunidade, após ter comparecido ao Serviço de Emergência do Município, e ter como diagnóstico inicial Artrose de membros inferiores. Não possuía história de acompanhamento médico prévio, visto que a Unidade de Saúde foi implantada há menos de sete meses, e não se recordava sequer ter feito consulta nos últimos 32 anos.

QP: “dor na perna direita”

HDA: Paciente refere dor em perna direita de forte intensidade que se iniciou em região maleolar externa irradiando-se para toda a extensão da perna e pé direito. Apresentou início súbito da dor há cinco dias, quando procurou auxílio médico no serviço de emergência do HMNSE, tendo sido medicado com analgésico e anti-inflamatório sem melhora clínica, retornou 2 vezes ao mesmo serviço com manutenção da conduta. Inicialmente refere que a dor era ao deambular, dificultando a marcha, com claudicação intermitente. Apresentou piora progressiva e no momento, com dor em decúbito e com parestesia em toda a região (perna e pé direito). Fato que merece consideração é o trajeto necessário para chegar em sua residência, visto que era obrigatório percorrer longa escadaria.

HPP: Refere Hipertensão Arterial Sistêmica há pelo menos 20 anos (sem tratamento). História de traumatismo aos 8 anos, quando fraturou joelho e pelve devido a queda de laje. Nega história de Diabetes Mellitus, Tuberculose ou Hepatite.

HF: Pais falecidos (não sabe informar causa). 
HS: Mora com uma irmã, de mesma idade e sua esposa reside em Pernambuco com seus dois filhos. Casa de tijolo e sem rede de esgoto. Água proveniente do poço artesiano. Etilista social. Tabagista com carga tabágica de 500 maços/ano.

Exame físico realizado: lúcido, orientado no tempo e espaço, corado, hidratado, acianótico, anictérico, eupnéico, afebril. Encontrava-se com pressão arterial de 160/100 mmHg MSD/DD; FC= 80 bpm, FP= 80 bpm, FR= 14 irpm. Tireóide impalpável, carótidas com pulsos amplos, sem sopros, jugulares atúrgidas a30. Ictus invisível e impalpável, ritmo cardíaco regular em três tempos com B4, bulhas hipofonéticas, sem sopro. Aparelho respiratório, tórax com diâmetro ântero-posterior aumentado, com Murmúrio Vesicular diminuído difusamente, sem ruído adventícios. Abdome flácidos, indolor à palpação superficial e profunda, peristáltico, apresentando massa de cerca de $5 \mathrm{~cm}$ de diâmetro em região periumbilical, pulsátil. Manobra de De Bakey positiva; outra massa circular em região inguinal direita de $2,5 \mathrm{~cm}$ de diâmetro também pulsátil, dolorosa a palpação. Membro inferior esquerdo com 84 centímetros e membro inferior direito com 91 centímetros de comprimento. Detectada, pois, diferença no comprimento de membros inferiores $(7 \mathrm{~cm})$. Pulsos poplíteos e pediosos assimétricos em amplitude e intensidade (ambos diminuídos, pulso em perna direita menor que perna esquerda). Perna direita com redução da temperatura em terço inferior, cianose de extremidade $\left(1^{+/ 4+}\right)$.

Crepitação em articulação dos joelhos à movimentação passiva. Escoliose tóraco-lombar para direita.

No mesmo dia foi contactada a médica supervisora de Clínica Médica que examinou prontamente o paciente, chegando a hipótese diagnóstica de Insuficiência Arterial em membro inferior direito devido a possível Aneurisma de Aorta abdominal agravado por embolia arterial. Nesse momento foi contactado o Serviço de Cirurgia Vascular do HMSA (RJ), que é tido como referência no caso descrito, uma vez que o Município de Petrópolis não dispõe de tal serviço. Ao mesmo tempo, a Secretaria de Saúde de Petrópolis, ciente de do caso, viabilizou a remoção para internação. Confirmado existência de Aneurisma de Aorta abdominal e artéria ilíaca direita causando insuficiência arterial aguda. Foram realizadas cirurgias de revascularização do membro afetado, amputação do segundo, 
terceiro e quarto pododáctilos que se encontravam necrosados, e em segunda ocasião, cirurgia para correção de aneurisma de aorta abdominal. Após período de internação, paciente foi contra-referenciado para a unidade de origem, onde continuou o acompanhamento pós-operatório e tratamento da hipertensão arterial.

\section{CONCLUSÃO}

As políticas de integralidade do fluxo de atendimento clínico e a hierarquização dos níveis de atenção à saúde oferecidos à população são de fundamental importância e devem estar em harmonia, visto que a atenção primária é insuficiente tecnologicamente para atender a problemas que trascendem sua capacidade resolutiva, dependendo, portanto, de nível de atenção de maior densidade tecnológica que lhe sirva de referência. A atenção primária exerce papel essencial como porta de entrada do sistema, influindo não só na acessibilidade do cidadão à saúde como também provendo redução de custos operacionais a níveis hierárquicos superiores. Porém pelo princípio da hierarquização é necessário um fluxo e contra-fluxo de pacientes e informações técnico-científicos entre esses diferentes níveis para que haja uma maior resolutividade. 